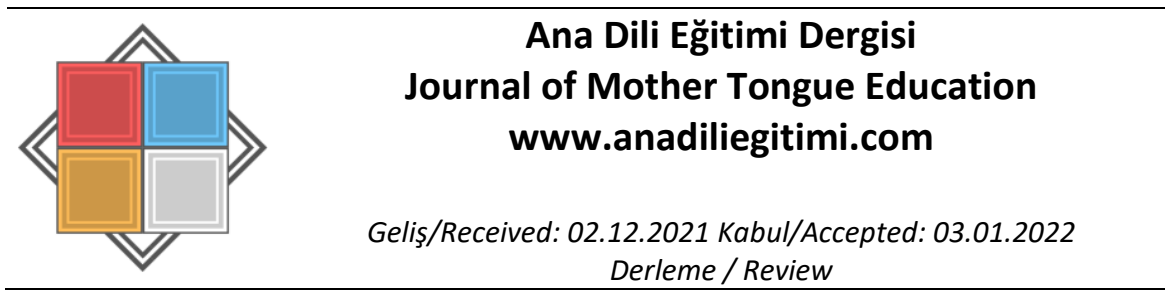

\title{
Akademik Tartışma Modeli: Boyutları ve Türkçe Derslerinde Uygulanması*
}

\author{
Kübra ÖZÇETIN ${ }^{* *}$ \\ Latif BEYRELi**
}

\begin{abstract}
Öz
Bu çalışmada sınıf içerisinde öğretmen-öğrenci ve öğrenci-öğrenci etkileşimiyle öğrenmeye katkı sağlayan ve iş birlikli öğrenmeye dayalı bir model olan Akademik Tartışma Modeli'nin (Accountable Talk) tanıtılması amaçlanmıştır. Her disiplinde (branşta) ve her sınıf düzeyinde uygulanabilecek olan bu modelde öğrenciler ele alınan konu hakkında, belirli kurallar dâhilinde birbirleriyle konuşarak yeni fikirler üretirler. Model kendine has kurallarıyla geleneksel tartışmadan farklılaşır. Sınıf ortamında çeşitli alt kategorilere ayrılan bu kuralların bir bölümü, bilginin doğruluğunu sağlamaya yöneliktir ve öğrencilerden bilgiyi sorgulaması, kaynağa dayalı bilgi sunması istenir. Bir bölümü muhakeme becerilerini geliştirmeye yöneliktir ve öğrencilerin görüşlerini gerekçelendirmelerini, dinledikleri iddiaları değerlendirmelerini, karşılaştırmalar yapmalarını, bunların mantıklı olup olmadığııı sorgulamalarını, tartışmada sunulan bilgilerle öne sürülen görüşleri sentezleyerek bir sonuca varmalarını sağlar. Bir bölümü ise öğrenmenin sınıf içi etkileşimle gerçekleşmesini ve öğrencilerin tartışma kurallarına uyarak, birbirlerinin görüşlerini dinleyerek yeni fikirler geliştirmelerini amaçlar. Uygulama sürecinde öğretmenler için hazırlanan "konuşma kalıpları" uygulamada öğretmenlere rehberlik yapmaktadır. Bu çalışmada modelin tanııımı, kapsamı ve içeriği hakkında bilgi verilmiş; ayrıca Akademik Tartışma'da öğretmenler için örnek konuşma kalıpları sunulmuştur.
\end{abstract}

Anahtar Kelimeler: Akademik tartışma modeli, okuma eğitimi, iletişim beceriler

\begin{abstract}
Accountable Talk: Its Dimensions and Implementation in Turkish Lessons Abstract

This study aims to introduce the Accountable Talk (AT) academic discussion model, which is a collaborative learning model that enables learning through teacher-student and student-student interaction in the classroom. AT is a model that can be applied in any subject area and at every grade level. Students generate new ideas by speaking with one another about a given topic following the sets of rules outlined in the model. One of these sets of rules aims to ensure the accuracy of the information in practice; students are asked to question the information and present source-based information. Another set aims to develop reasoning skills, how students justify their views, and how they evaluate the claims presented by assessing them and making comparisons. Thus, students are empowered to come to a conclusion by synthesizing the presented information with the views put forward during the conversation. Another set of rules aims to enable learning to occur through the interaction of all students so that they may develop new ideas by listening to each other's perspectives and following the general discussion rules. The "speech patterns" prepared for teachers during the implementation phase guide them in the process. This study
\end{abstract}

\footnotetext{
* Bu çalışma, birinci araştırmacının ikinci araştırmacı tarafından yönetilen "Akademik Tartışma Modelinin Türkçe Derslerinde Kullanılabilirliği Üzerine Bir Durum Araştırması” adlı doktora tezinden (2019) üretilmiştir.

** Arş. Gör. Dr., Marmara Üniversitesi, Atatürk Eğitim Fakültesi, Türkçe ve Sosyal Bilimler Eğitimi Bölümü, İstanbul, kubra.ozcetin@marmara.edu.tr, ORCID: orcid.org/0000-0002-5485-1586

*** Prof. Dr., Marmara Üniversitesi, Atatürk Eğitim Fakültesi, Türkçe ve Sosyal Bilimler Eğitimi Bölümü, İstanbul, beyreli@marmara.edu.tr, ORCID: orcid.org/0000-0002-0130-3332
} 
introduces the model and presents information about its content. In addition, speech patterns for teachers are included.

Keywords: Accountable talk model, reading education, communication skills

\section{Giriş}

Sınıf içerisinde öğrenci-öğrenci diyaloğu ve öğretmen-öğrenci diyaloğunun öğrenme sürecindeki etkileri konusundaki çalışmalar son zamanlarda özellikle Amerika'da ve Avrupa ülkelerinde yoğunluk kazanmıştır. "Sınıf söylemi (classroom discourse) kapsamında yapılan bu tür çalışmalardan bazıları şunlardır: Cazden, vd., 1972; Cazden, 1986, 1988; Wertsch, 1985; Green ve Wallat, 1989; Moll, 1990; Gee, vd., 1992; Cochran-Smith vd., 1993; Bloome, 1998; Wells, 2000; Cope vd., 2000." (Michaels ve O'Connor, 2015, s. 334). Sınıf söylemi alanı; öğrencilerin sınıfta ne kadar süre konuştuğu, iletişim sürecinde konuşma sırasının ne sıklıkla değiştiği, söylemlerin içeriği vb. konuları inceleyerek daha etkili bir öğrenme ortamı için neler yapılması gerektiği ile ilgili araştırmaları içermektedir. Etkinlik temelli öğretim yaklaşımıyla öğrencilerin öğrenme sürecinde öğretmenle ve sınıf arkadaşlarıyla etkileşim hâlinde olmaları ve kurdukları diyaloglar ile de öğretim sürecine aktif katılmaları sağlanmaktadır. Öğrencilerin sunulan bilgiler üzerine düşünerek, yorum yaparak, arkadaşlarının düşüncelerini dinleyip değerlendirerek bir sonuç çıkarmaya çalışmaları öğrenme sürecinde kalıcılığı artırmaktadır. Öğrencilerin düşünerek sonuca ulaşması, sonucun hazır olarak kendilerine verilmesinden daha etkili olmaktadır. Bu bağlamda öncelikle sınıf içi konuşma uygulamalarının hâlihazırdaki durumunu ortaya koymak önem arz etmektedir. "Kimi araştırmacılar sınıf içi konuşmaların özelliklerini konu edinen çalışmalar yapmışlardır: Cazden, 2001; Edwards ve Westgate, 1994; Heyman, 1983; Lemke, 1990; O'Connor ve Michaels, 1993, 1996; Tharp ve Gallimore, 1991." (Learning and Research Development Center, 2006, s. 1). Bu araştırmalarda sınıf içi diyalogların şu şekilde gerçekleştiği belirlenmiştir: Öğretmen bir soru sorar ve bir öğrenciden cevap vermesini ister. Öğretmen öğrencilerden duymak istediği cevabı alana kadar soru sormaya devam eder veya kendisi doğru cevabı söyler. Bu süreç; "soru sorma-cevap verme-değerlendirme" döngüsüne sahipse IRE (Initiation-Response-Evaluation); "soru sorma-cevap verme-dönüt" döngüsüne sahipse IRF (Initiation-Response-Feedback) olarak adlandırılmaktadır. Cazden bu söylemlerin sınıflarda en yaygın kullanılan konuşma söylemleri olduğunu belirtmiştir (2001, s. 30). Bu şekilde devam eden bir konuşmada öğrenci, öğretmenin sorusuna doğru cevap verdiyse olumlu dönüt alır, yanlış cevap verdiyse öğretmen doğru cevabı söyler veya ipucu verir ya da soruyu başka bir öğrenciye tekrar sorar. Bütün bu olasılıklarda öğrencinin sınıfta konuşma süresi oldukça sınırlı kalmaktadır. Bu durumun telafisi için sınıflarda mümkün olduğunca tartışma ortamları oluşturulmalıdır. Tartışma yöntemi kullanılan bir sınıfta zamanla öğrenciler kendi başlarına bir diyaloğu başlatıp sürdürebilme becerisi kazanabilmektedir. Öğretmenin bu süreçte bu diyalogları takip ederek gerekli yerlerde müdahale etmesi beklenir.

Ders kitaplarında öğrenciler için tartışma konusunu belirleme, tartışmayı başlatma, yürütme etkinlikleri sistematik bir biçimde yer almamaktadır. Dolayısıyla öğretmenlerin nitelikli bir tartışma ortamı oluşturmaları tamamen kendi mesleki becerilerine bağlıdır. Bu nedenle ayrıntılı bir şekilde planlanmış, kurallı, sistematik tartışma yöntemlerinin hazırlanmasına ve öğretimde kullanılmasına intiyaç duyulmaktadır.

Türkçe derslerinin ana malzemesi metinlerdir. Metinlerin daha iyi anlaşılması, öğrencilerin iletişim becerilerinin geliştirilmesi ve sınıfta etkili bir öğrenme ortamı oluşturulması metin üzerine tartışma yapılarak sağlanabilir. Bu bağlamda metin üzerine tartışma ile ilgili birçok yöntem geliştirilmiştir: "1. Eğitici Konuşma (Instructional Conversations-IC) (Goldenberg, 1992, 1993), 2. Junior Great Books, Birlikte Sorgulama (Shared Inquiry, Great Books Foundation, 1987), 3. Yazarın Sorgulanması (Questioning the Author-QtA) (Beck ve McKeown, 2006), 4. Işsbirlikli Muhakeme (Colloborative Reasoning-CR) (Anderson, Chinn, Waggoner ve Nguyen, 1998), 5. Paideia Seminerleri (Paideia Seminars) (Paideia eski Yun. yaygın kültürel eğitim) (Billings ve Fitzgerald, 2002), 6. Çocuklar İçin Felsefe (Philosophy for Children- P4C) (Sharp, 1995), 7. Kitap Kulübü (Book Club) (Raphael ve McMahon, 1994) vb." (Özçetin, 2019). Bu yöntemlerin birbirlerinden farklı özellikleri bulunmakla birlikte hepsinin ortak noktası öğrencilerin ortak bir metin üzerinde birbiriyle tartışarak metni anlamalarını, eleştirel düşünme ve iletişim becerilerini geliştirmeye çalışmalarıdır. Öğrenciler metne 
yönelik sorular sormaya başladıklarında metni anlamanın ötesine geçerek metin üzerine düşünceler üretmeye başlarlar ve ilk okuyuşta göremeyecekleri ayrıntıları fark ederler. Öğrencilerin metin üzerine tartışmaları kadar önemli bir konu da nasıl tartışacaklarını bilmeleridir. Öğrenciler tartışma sırasında görüşlerini ifade edebilir, metinde yer alan düşüncelerle ilgili bazı sonuçlar çıkarabilirler fakat tartışmanın sağlıklı ve üretici olması için belirli kurallar dâhilinde yürütülmesi gerekir. Öğretmenlerin uygun bir sınıf ortamı oluşturmaları ve metin üzerine yapılan tartışmayı başarılı bir şekilde yönetmeleri, öğrencilere tartışmayı ve metni sorgulamayı öğretmeleri gerekir. Metinler üzerine bu şekilde çalışmaya alışan öğrenciler bir süre sonra kendilerini yönlendiren birisi olmadan da bir metni yorumlayabilir, metne sorular sorabilir, arkadaşlarına sorular yöneltebilir. Tartışma kurallarına uygun olarak metinde dikkatini çeken noktalar üzerine konuşan, arkadaşlarının düşüncelerini saygıyla dinleyen bir öğrenci, hayata hazır bir birey olacaktır. Tartışma kültürü edinmek için en uygun yer okullardır. Okul hayatı boyunca kendini ifade etme alışkanlığı kazanmamış bir bireyin toplumda kendini ifade edebilmesi beklemek mümkün değildir. Sınıfların kalabalık olması, öğrencilerin sadece kendilerine söz hakkı verildiğinde konuşmaları ve sadece soru sorulduğunda cevap vermeleri nedeniyle öğrencilerin kendilerini ifade etmek için yeterli zamanları ve imkânları bulunmamaktadır. Sınıf ortamında tartışma uygulaması yaptıran öğretmenler, tartışma sırasında yaşanacak olası durumları hesaplamalıdır. Öğrencilerin konu dışına çıkmalarının ve tartışmayı günlük sohbete benzer bir şekle dönüştürmelerinin önüne geçilmelidir.

Üretici tartışmada her öğrencinin katkı sunmasıyla bir öğrencinin kendi kendine öğrenemeyeceği kadar bilgi öğrenilebilir. Öğrencilerin tartışmaya katkıları; kaynaklardan alıntılar ya da metne dayalı görüşler biçiminde olabilir. Bu kaynakların nasıl sunulacağı, kanıtların doğruluğu, işlevselliği, öğrencilerin konuşma süreleri, konuşma sırasının ayarlanması, söz alma kuralları, başkalarının görüşlerini dinlemeleri, dinledikleri görüşleri sorgulamaları ve konuşmalarını o görüşlere cevap niteliğinde sunmaları vb. birçok konu üzerine çalışılarak bir tartışma uygulamasının planlanması ve yürütülmesi önem arz etmektedir. Akademik Tartışma (AT) işte bu öneme binaen oluşturulmuş bir tartışma modelidir.

Akademik Tartışma ile ilgili yapılan bazı çalışmalar ve ulaşılan sonuçlar şunlardır: AT ile ilgili çalışmalar yapan araştırmacılar; AT'nin öğrencilerin iş birlikli öğrenmelerine ve görüşlerini gerekçelendirerek sunmalarına katkı sağladığı (Chapin ve O'Connor, 2004; Richardson, 2017), bir grup/birlik duygusu oluşturduğu (Gillies, 2014; Howell, Thomas ve Ardasheva, 2011) sınıfta yer alan öğrencilerin kendi bireysel görüşlerini öne sürmeleri yerine arkadaşlarının görüşleriyle bağlantılı cümleler kurdukları, "hazır konuşma kalıpları"nı kullanmalarıyla birlikte bilgiyi sorguladıklarını, akademik dil kullanımlarının ve (Monaghan, 2015; Guardado 2017), eleştirel düşünme becerilerinin geliştiği (Wolf, Crosson ve Resnick, 2006; Ouellette, Kathleen M. 2006), sınıfta güçlü bir etkileşim sağlandığı ve konuşma/dinleme kazanımları için uygulanabilecek başarılı bir sınıf söylem stratejisi olduğu (Martello, 2015), öğrencilerin birbirlerinin sözünü kesmeden saygıyla birbirlerini dinlemelerini (Carpenter, 201; Pantaleon, 2016), öğrencilerin okuduklarını daha iyi anlamalarını (Richardson, 2010), öğrencilerin görüşlerini metinden alıntılarla destekleme alışkanlığı edinmelerini (Guardado, 2017; Carpenter, 2014), görüşlerini gerekçelendirmelerini ve diğer öğrencilerden de görüşlerini gerekçelendirmelerini talep etmelerini sağladığı (Michaels ve O'Connor, 2015; Bellamy, 2016) şeklinde sonuçlara ulaşmışlardır.

\section{Akademik Tartışma Modeli}

Öğrencilere metin üzerine tartışarak metni birçok yönüyle inceleme fırsatı veren bir tartışma modeli olan AT; (Accountable Talk $\left.{ }^{\mathrm{SM} 1}\right)^{2}$ Lauren Resnick, Sara Michaels ve Catherine O'Connor

\footnotetext{
${ }^{1}$ Bu terimin patenti Pittsburgh Üniversitesine aittir.

${ }^{2}$ Accountable" kelimesi "açıklanabilir", "mesul”, "sorumlu", "hesap verilebilir" anlamlarına gelmektedir. Modeli oluşturan araştırmacılardan Sarah Michaels ve Suzanne Chapin'den bu terime Türkçede kavramsal karşılık için tavsiye istendiğinde "akademik üretici tartışma" (Academically Productive Talk) karşılığını önermişlerdir. Resnick, "akademik" kelimesinin kullanılmasına sıcak bakmadığını çünkü modelin akademik dil dışında informal dil kullanımını da içerdiğini belirtmiştir. Ancak, öğrencilerin bu modelde, bilimsel kaynaklar kullandıkları, bilginin
} 
tarafından 1997 yılında oluşturmuştur ve Pittsburgh Üniversitesi Öğrenme Enstitüsünün öğrenme ilkelerinden (Principles of Learning(C) biridir. Resnick, Öğrenme Enstitüsünde (Institute for Learning) yaptığı araştırmalar sonucunda öğretme ve öğrenme profillerini (Instruction and Learning Profiles(C) belirlemiş ve buradan hareket ederek "Öğrenme IIlkeleri" ni (Principles of Learning@) oluşturmuştur. AT öğrencilerin eleştirel düşünme, konuşma ve dinleme becerilerini birlikte geliştiren bir yöntemdir. Martello çalışmasında (2015), AT’nin, konuşma ve dinleme kazanımlarının edinilmesi için uygulanabilecek başarılı bir sınıf söylem stratejisi olduğunu belirtmiştir.

\section{Akademik Tartışma Modelinin Boyutları}

"AT, Vygotsky'nin kişinin zihinsel süreçlerinin gelişiminde sosyal etkileşimin önemini vurgulayan "sosyal aklın oluşumu" (social formation of mind) teorisine dayanılarak oluşturulmuştur (Michaels, O'Connor ve Resnick, 2008, s. 285)." Öğrencilerin birbirleriyle etkileşim hâlinde öğrenmeleri ve birikimli bir bilgi oluşturmalarını temel alan bu yaklaşıma göre her konuşma kendiliğinden öğrenmeyi sağlamaz. Konuşmaların öğrenmeyi sağlaması için bazı niteliklere sahip olması gerekir. Bu nitelikler AT'nin 3 boyutunda/aşamasında ele alınmaktadır (Michaels, O'Connor, Hall ve Resnick, 2010, s. 1):

- öğrenme topluluğuna karşı sorumluluk (ÖTKS),

- bilginin doğruluğuna karşı sorumluluk (BDKS),

- etkili düşünmeye karşı sorumluluk (EDKS).

Bu 3 boyuttan ÖTKS, öğrencilerin sınıf ortamında demokratik tartışma kurallarını uygulamaları ve metin üzerine yapılan konuşmaların birbiriyle bağlantılı hâle getirilmesini kapsar. BDKS boyutunda, tartışma sırasında sunulan bilgilerin doğru, nitelikli ve konuyu açıklığa kavuşturabilecek, işlevsel bilgiler olması dikkate alınır. Doğru bilgilerin sunulması kadar bu bilgileri kullanmak da önemlidir. Tartışma sırasında sunulan bilgilerin ve ortaya konan görüşlerin sentezlenerek sonuçlara varılması, tartışma sırasında öğrenilen her yeni bilgiyi kullanarak mantıkı sonuçlara ulaşmak modelin EDKS boyutuyla ilgilidir. Bu boyut öğrencilerin muhakeme gücünü geliştirmeyi amaçlar. Modelin üç boyutunun etkili bir şekilde birlikte kullanılmasıyla sağlıklı bir tartışma ortamı ve bunun sonucu olarak nitelikli bir öğrenme meydana gelir.

\section{Öğrenme Topluluğuna Karşı Sorumluluk (ÖTKS) (Accountability to the Learning Community)}

Öğrenme Topluluğu (Learning Community) sınıfta/tartışma grubunda yer alan öğrencilerdir. Öğrencilerin birlikte öğrenmelerine işaret eden bir boyuttur. Bu kapsamda, öğrencilerden biri bir soruya cevap verdiğinde veya metinle ilgili bir fikir öne sürdüğünde söylediklerini diğer öğrencilerin de dinlemesi, değerlendirmesi ve cevap vermesi beklenir. Bu aşama, öğrenciler arasında diyalog oluşturulmasını sağlar. Geleneksel sınıf içi tartışma uygulamalarında öğrenciler genellikle birbirlerinin ne söylediğiyle ilgilenmeyerek sadece öğretmene cevap vermeye çalışırlar, öğrencilerin diğer öğrencilerin konuşmalarına karşılık verme imkânları yoktur. Oysa öğrencilerin birbirlerinin cevaplarını yorum yaparak zenginleştirmeleri, üzerine eklemeler yapmaları, değerlendirmeleri, gerektiğinde arkadaşlarına ek sorular sormaları metinle ilgili daha derin anlamların keşfedilmesini sağlar.

kaynağını sorguladıkları, yetersiz bulduklarında ek bilgi istedikleri, gerekli bilgiye nasıl ulaşabileceklerini araştırdıkları, birbirlerinin söylediklerini dikkate alarak, kendi düşüncelerini de ekleyerek bu düşünceleri geliştirmeye çalıştıkları, geçersiz kanıtları sorguladıkları için tarafımızca "akademik tartışma" olarak adlandırılmışır. Birebir çevirisi olan "sorumlu konuşma", "açıklayıcı konuşma" gibi adlar tartışmanın içeriğini tam olarak yansıtmamaktadır. Bu nedenle birebir çeviri olmayan fakat modelin içeriğine uygun bir adlandırma yoluna gidilmiştir.

3 Öğrenme illkeleri şunlardır: 1. Performansı Düzenlemek (Organizing for Effort), 2. Akademik Tartışma (Accountable Talk), 3. Açık Beklentiler (Clear Expectations), 4. Usta-Çırak iliş̧kisiyle Öğrenme (Learning as Apprenticeship), 5. Sosyalleşme Yoluyla Zekâ Geliştirme (Socializing Intelligence), 6. Adil ve Güvenilir Değerlendirmeler (Fair and Credible Evaluations), 7. Düşünme Sürecinde Akademik Titizlik (Academic Rigor in a Thinking Curriculum) 8. Öğrencinin Kendi Öğrenmesini Yönetmesi (Self-Management of Learning), 9. Başarının Onaylanması (Recognition of Accomplishment) 
Öğrencilerin metin hakkında birlikte konuşarak yeni sonuçlara ulaşmaları, bilgi üretmeleri ile ilgili kurallar ÖTKS aşamasında tanımlanır.

Bir konuşmaya ciddi şekilde katılan ve başkalarının fikirleri üzerine kendi fikirlerini inşa eden öğrenciler; birbirlerini dikkatli bir şekilde dinler, birbirlerinin görüşlerine katkıda bulunur, birbirlerine soru sorarlar ve böylece ortaya atılan görüşler sürekli olarak detaylanır ve zenginleşir (Michaels, O'Connor ve Resnick, 2008, s. 286). ÖTKS boyutunda öğrenciler sadece sessiz olmaya dikkat edip konuşma sırasının kendilerine gelmesini beklemezler, aynı zamanda kendi görüşlerini belirtmek ve tartışmaya katılmak için birbirlerini dikkatle dinlerler. Hem öğrenciler hem öğretmen, ifade edilen görüşleri özetler ve ilave argümanlarla genişleterek tartışmaya katkıda bulunurlar. Öğrenciler bir arkadaşının görüşünü tam olarak anlamadığında onu açıklığa kavuşturmak için çaba sarf ederler. Ayrıca katılmadığı bir görüş karşısında eleştirilerini saygılı bir şekilde ifade ederler. Görüşün sahibine değil, görüşe meydan okurlar. Öğrenciler bazen kendi kendilerine bazen de öğretmenin yardımıyla tartışmayı yürütürler (Michaels, O'Connor, Hall ve Resnick, 2010, s. 2).

Metin üzerine tartışma yapılırken bazı öğrenciler arkadaşlarına göre daha baskın olabilmektedir. Görüşlerini ifade etmeye alışıın olan, dışa dönük, cesaretli öğrencilerin arasında geçen bir konuşma ortamı diğer öğrencilerin öğrenmelerini olumsuz etkiler. Bu durumda içe dönük, çekingen, dersle/konuyla ilgili olmayan öğrencilerin de tartışmaya katılmaları için farklı uygulamalar yapılmalıdır. "içe dönük öğrencilerin öncelikle küçük grup tartışmalarında yer alıp daha sonra büyük grup tartışmalarına katılmaları özgüvenlerinin artmasını sağlamaktadır (Cain, 2012'den akt. Pantaleon, 2016. s. 45). Yazma ve çizme, resim (drawing) gibi uygulamalar da içe dönük öğrencilerin kendilerini rahat hissetmesini sağlayan diğer yollardır. İçe dönük öğrenciler yakın arkadaşlarıyla oluşturulan gruplarda kendilerini daha rahat hissetmektedir. Bu tür öğrencilerin tartışma sırasında AT kalıp ifadelerini (Katılıyorum, çünkü ... vb.) kullanmaları tartışmaya katılımlarını olumlu yönde etkilemektedir. Kimi öğrenciler, bu kalıp ifadeleri kullanmakta zorlanmaktadırlar, çünkü tartışmada kendini ifade etmekte zorluk yaşarken bir yandan da bu kalıp ifadeleri kullanmak onlar için oldukça zor olmaktadır (Cain 2021'den akt. Pantaleon, 2016, s. 39). Bununla birlikte düşük sosyo-ekonomik düzeydeki ailelerden gelen öğrencilerle yüksek sosyo-ekonomik düzeydeki öğrenciler arasında demokratik bir ortam yaratarak görüşlerini rahat bir şekilde sunmaları sağlanmalıdır (Michaels ve O'Connor, 2015, s. 334).

Öğrenciler tartışma sırasında akılarına gelen bir düşünce olduğunda bu düşünceyi bir an önce paylaşma isteğiyle arkadaşlarının sözünü kesebilirler. Öğrencilerin birbirlerinin sözünü kesmeden görüşlerini ifade etmeleri ve birbirlerini saygılı bir şekilde dinlemelerini sağlamak için kurallar oluşturulmalıdır. Yeni bir fikir öne sürerken yetişkinler bile kendilerini ifade edebilmek için zaman zaman desteğe, cesaretlendirilmeye ihtiyaç duyarlar.

Öğrencileri kısıtlı bir zaman aralığında belirli standartlara ulaştırmaya çalışan öğretmenler, dersin hedeflerini yerine getirmeye özellikle dikkat etmelidir ve konunun dağılmasını engellemelidir. Ders sırasında bazen bir öğrencinin sıra dışı bir yorum dile getirmesi, alışılmadık bir kanıt sunması, belirli bir terimin anlaşılmaya çalışılması, bir deneyden beklenmedik bir sonuç çıkması gibi planlanmayan durumlar gerçekleşebilir. Öğretmenlerin böyle durumlarda dersi, asıl konu üzerinde sürdürmek veya oluşan yeni durumun sağlayacağı öğrenme ortamına yönelerek sürdürmek arasında yerinde ve doğru bir seçim yapması ve ders sırasındaki bu ani değişimlerin yararlarını ve zararlarını değerlendirmeleri gerekmektedir. Ders boyunca öğrencilerin aktif bir şekilde birbirleriyle konuşmaları, her öğrencinin uygun ses tonu ve içerikle farklı konuşma aktivitelerine katılması (akran tartışması, bütün sınıf tartışması vs.), öğrencilerin birbirlerini dikkatle dinlemeleri, birbirlerinin sözünü kesmemeleri, diğer öğrenciler konuşurken dikkatlerini konuşan öğrenciye yoğunlaştırmaları gerekir. Karşılıklı saygı ve güvene dayalı ortam oluşturulmalı, bir görüş hakkında değerlendirme yaparken, karşıt görüş bildirirken kişiler hedef alınmamalı, görüşün kendisine yönelik eleştiri yapılmalıdır. Öğrenciler, kendilerinden önce konuşan arkadaşlarının söylediklerini anladıklarından emin olmalı, gerektiğinde daha iyi anlamak için sorular sormalıdır. Öğrenciler, görüşlerini bu şekilde birbirlerine açıklamaya çalışırken kendiliğinden ortaya çıkan bu tartışma ortamında daha derinlikli fikirler üretebilirler. Öğretmen böyle bir tartışma ortamı oluşturmak için gerekli zemini hazırlar (Michaels, O'Connor, Hall ve Resnick, 2010, s. 3). 
Bilginin Doğruluğuna Karşı Sorumluluk (BDKS) (Accountability to Accurate Knowledge)

Akademik tartışmada öğrencilerin bilgiyi kullanması beklendiği hâlde büyük bir çoğunluğunda sağlam bir bilgi temeli bulunmayabilir. Bu nedenle tartışmanın temel amacı; öğrencilerin ihtiyaçları olan doğru ve tutarlı bilgiyi edinmelerini sağlamak, bununla birlikte akademik dil kullanımını geliştirmek ve muhakeme kurma becerisi kazandırmaktır (Michaels, O'Connor ve Resnick, 2008, s. 289). insanların araştırmadan, kaynaklara dayanmadan bilgi sunmaları ve aynı şekilde karşılaştıkları bilgilere hiç sorgulamadan inanmaları bilgi kirliliğine yol açar. Bir metin hakkında tartışma yapılırken farklı öğrenciler tarafından sunulan bilgiler üzerine yeni fikirler inşa edileceği için bu bilgilerin doğru ve tutarlı olması, tartışma sonunda ulaşılan sonuçların doğruluğuna katkı sağlayacaktır. BDKS aşamasına göre, konuşmacı görüşlerini ifade ederken veya bir iddia ortaya atarken aklına gelen herhangi bir şeyi söylemek yerine konuyla doğrudan ilgili ve doğrulanmış bilgiler sunmalıdır. Burada konuşurken sürekli olarak kaynaklara atıf yapmak, bilginin doğruluğunu garanti edebilecektir. Bu süreçte, atıf yapılan kaynağın niteliği gözden geçirilmelidir. "Öğrencilerin atıf yaptıkları kaynaklar; bir kitap, belgesel, röportaj, ders kitabı veya kişisel deneyimleri sonucunda elde ettikleri bilgiler olabilir. İddiaları desteklemek için öne sürülen bilgiler özel bilgiler (spesifik) olmalı ve başkalarının da tasdik edeceği bilgilerden meydana gelmelidir. BDKS sürecinde, öğrenciler ve öğretmenler desteklenmeyen iddiaları sorgularlar, iddiaların desteklenmesi için bilgi, veri, örnek talep ederler, kimi terimlerin tanımlanmasını isterler. Ek bilgi gerekip gerekmediğini gözden geçirirler, gerekiyorsa iddiaların dayanaklarına dönük olarak kanıt talep ederler ve bir problemi çözerken ilerleme kaydetmek için gerekli bilgiyi nasıl ve nereden bulacaklarını tartışırlar. Öğretmenler, öğrencilerin kazandıkları bu becerileri sürdürebilmeleri için zaman harcarlar ve çaba sarf ederler." (Michaels, O'Connor, Hall ve Resnick, 2010, s. 4).

Tartışmada her öğrenci doğru bilgi sunma konusunda sorumlu olduğu gibi aynı zamanda yeni bilgiyi değerlendirebilmelidir.

"Öğrencilerin birbirlerine:

- Bu istatistikler doğru mu?

- Bu sonuca neye dayanarak ulaştın?

- Bahsettiğin durum metinde nerede geçiyor?

- Bunu kim söyledi?

- Bu olay ne zaman gerçekleşti?

- Bu yorumunu destekleyebileceğin yazılı bir metin/kaynak var mı? şeklinde zorlayıcı sorular sormaları gerekir. Bu sorulara, üzerinde tartışlan metnin bir bölümünden alıntı yaparak veya tartısma sırasında ortaya çıkan bilgilere dayanarak cevap verilmelidir. Öğrenciler bildiklerinden yola çıkarak açıklamalar yapabilir. Sınıfta tartışma esnasında üretilen bilgilerin dışında bir bilgi sunduğunda da bu bilginin doğru, konuyla ilgili ve erişilebilir (bütün grubun ulaşıp atıf yapabileceği) özellikte olmalıdır. Tartışmada BDKS boyutu gereği, hem öğretmen hem de ögrrenciler sundukları iddiaların doğru ve gerçek olması konusunda kendilerini sorumlu hissederler. Öne sürdükleri görüşü desteklemek için sınıfta daha önce yapılan tartışmalardan elde edilen sonuçlara atıf yapabilirler. Daha önce birlikte tartıştıkları konular, daha sonraki tartışmalarında tartıştıkları konuyla ilgiliyse bu konulara atıflar yaparlar. Böylece öğrenme topluluğu tarafından birikimli bir bilgi oluşturulur." (Michaels, O'Connor, Hall ve Resnick, 2010, s. 4).

\section{Etkili Düşünmeye Karşı Sorumluluk (EDKS) (Accountability to Rigorous Thinking)}

Bu boyut, konuşmada mantığı kullanarak bağlantılar kurmayı ve muhakemeye dayalı sonuçlar çıkarmayı kapsar (Michaels, O'Connor ve Resnick, 2008, s. 286). Öğrencilerin muhakeme yapmak için metinde yer alan bilgileri etkili bir şekilde kullanmaları gerekir. Bu nedenle bu aşama BDKS ile doğrudan ilişkilidir. "BDKS aşamasında gerekli ve doğru bilgileri elde etmek önemliyken EDKS aşamasında ise tartışmayı yapılandırmak önemlidir. Bunun için tutarlı ve özenli bir şekilde öne sürülen farklı görüşler ve kanıtlar arasında bağlantılar kurmak gerekir. Öğretmen, öğrencilerin düşüncelerini net bir şekilde ifade etmeleri için onları varsayımlar üzerinde düşünme, açıklamalar yapma ya da tahminde bulunma vb. düşünme aktivitelerine yönlendirir. Öğretmen aynı zamanda öğrencilerin görüşlerini kanıtlarla 
desteklemelerini ve gerekçelendirerek ifade etmelerini ister (Michaels, O'Connor, Hall ve Resnick, 2010, s. 5).

"Yanlış bir bilgi ile de mantıklı bir iddiada bulunulabilir, güçlü bir mantık önermesi kurulabilir. Bir kanıtın yetersiz veya yanlış olabileceği gibi iyi araştırımış, doğru bilgiler içeren bir kanıtın da öne sürülen iddia ile doğrudan bir ilgisi olmayabilir. Burada kanıt olarak sunulan bilgi doğru olsa da tartışmayı bir sonuca ulaştırmaz, konuşmaya katkı sağlamaz. Tartışmada kanıtlar şu sorularla irdelenir:

- Bu iddia yeterince desteklenmiş mi?

- Kanıt, iyi mi, yeterli mi, güvenilir mi, ilgili mi, tarafsız mı?" (Michaels, O'Connor, Hall ve Resnick, 2010, s. 6).

Sağlam ve titiz bir şekilde inşa edilmek istenen tartışmalarda, öğrenciler içeriği anlayıp anlamadıkları konusunda kendilerini test ederler, kavramları yeniden tanımlarlar ya da gerekiyorsa daha önce yapılan açıklamaları değiştirirler ve böylece konu ile ilgili kendi görüşlerini belirlerler. Kanıt olarak sunulan görüşler arasında karşılaştırmalar yaparlar, zıtlıkları tespit ederler, kanıt ve iddiaları ne derecede kabul ettiklerini ifade ederler. Öğrenciler bir iddia ortaya atmak ve bunu desteklemek için veriler kullanırlar; örnekler, benzetmeler sunarlar, "Şöyle olsaydı ne olurdu?" şeklinde senaryolar oluşturarak hipotezler kurarlar. EDKS aşamasının uygulandığı bir sınıfta içerik ne olursa olsun asıl amaç; tam olarak açıklanabilen, herkese sunulabilecek, daha sonra başkaları tarafından kontrol edilebilecek ve sorgulanabilecek ve daha da geliştirilebilecek nitelikte iddiaların oluşturulmasıdır (Michaels, O'Connor, Hall ve Resnick, 2010, s. 6). “EDKS aşamasında, "öğrenciler, iddialarını muhakemeden geçirerek mantıklı bir şekilde sentezlerler ve kanıtların niteliğini değerlendirerek sonuca ulaşmaya çalışırlar." (Tegos, Demetriadis, Karakostas, 2015, s. 310).

"Tartışma sırasında düşünceye dayalı ifadeler ve gerekçelendirme kullanılmalıdır. Çok az öğrenci iyi temellendirilmiş kanıtlara dayalı iddialarla konuşur. Bu durumda bazı öğrenciler okul hayatını hiç entelektüel bir görüş sunmadan sadece öğretmenin sorularına basit cevaplar vererek geçirirler. Öğretmen, öğrencilerin bu konudaki yeteneklerini geliştirmede kritik bir rol oynar (Michaels, O'Connor, Hall ve Resnick, 2010, s. 26).

"AT'de EDKS aşamasına göre, öğretmen ve öğrenciler sunulan kanıtları eleştirel bir şekilde incelerler. Ancak kanıtların aşağıdaki esaslara uygun olması önemlidir:

- Kanıtlar kaliteli ve değerli olmalıdır.

Erzurum ve Artvin'de yaşayan insanlar hakkındaki bilgi, İzmir'de yaşayan birkaç insan üzerinde yapılan informal bir araştırmaya veya Türkiye'ye öğrenci değişim programıyla gelen bir öğrencinin bilgilerine dayanmamalıdır. ${ }^{5}$

- Kanıtlar güvenilir olmalıdır.

Bir gazeteden veya dergiden elde edilen bilgi, bilinmeyen bir kaynaktan alınan bilgiden, kaynak göstermeyen bir internet haberinden daha güvenlidir. ${ }^{6}$

- Anlatılanlar mutlaka iddialarla ilgili olmalıdır.

Japonlar hakkında verilen bilgiler ne kadar doğru olursa olsun, Kuzey Amerikalılar veya Avrupalılar hakkında yapılan bir tartışmada etkili olmayacaktır. ${ }^{7}$ (Michaels, O'Connor, Hall ve Resnick, 2010, s. 5)."

Informal tartışmalarda öğrenciler öne sürdükleri görüşleri, varsayımları açık bir şekilde sunmayabilirler veya açık bir şekilde ifade edilmemiş cümleler kullanabilirler. Öğretmenler AT'de açıklayııı bir şekilde konuşmalarını sağlamalı ve bu süreçte kazandıkları alışkanlıkları sınıf dışında da kullanmaları yönünde öğrencileri yönlendirmelidir. Örneğin bir öğrenci bir araştırma projesini ailesine veya arkadaşlarına anlatırken birisi ona bu araştırmayı nasıl yaptığını, çalışmasının arka planını sorabilir. Bazı terimleri veya hususları açıklamasını isteyebilir. AT'de amaç görüşlerin sunulacağı, grupta yer alan

\footnotetext{
${ }^{5}$ Bu örnek alıntı yapılan kaynakta şu şekilde geçmektedir: Kuzey Amerika ve Avrupa'da yaşayan insanlar hakkındaki bilgi, Chicago'da yaşayan birkaç insan üzerinde yapılan informal bir araştırmaya veya Paris'e öğrenci değişikliğiyle giden bir öğrencinin bilgilerine dayanmamalıdır.

${ }^{6}$ Bu örnek alıntı yapılan kaynakta şu şekilde geçmektedir: Washington Post'tan elde edilen bir bilgi, bilinmeyen bir kaynaktan alınan bilgiden, kaynak göstermeyen bir internet haber bülteninden daha geçerlidir.
} 
diğer kişilerin bu görüşleri sorgulayacağı ve böylece yeni fikirlerin geliştirileceği bir ortam yaratmak ve düşünceleri geliştirmektir. Süreçte, öğrencilerin düşünce geliştirme yollarını öğrenmelerini ve akıl yürütme kabiliyetlerini geliştirmeleri, görüşlerini açıkça ifade etmeleri, başkalarının katkılarıyla daha açık hâle gelmiş, detaylandırılmış görüşler üretmeleri, inandırıcı ve ikna edici görüşler oluşturmaları, daha derinlikli düşünmeleri, sorgulamaları, kanıtların yeterliliğini değerlendirmeleri ve bakış açılarının çeşitliliğini sağlamak amaçlanır (Michaels, O’Connor, Hall ve Resnick, 2010, s. 9).

\section{Akademik Tartışma Modelinin Planlama ve Uygulama Süreci}

AT, bütün uygulamalar gibi öncesinde bir hazırlık süreci gerektirmektedir. Uygulamada her öğretmenin aynı başarıyı gösteremediği görülmektedir. "AT'yi uygulayan öğretmenler; öğrencilerin görüşlerini başkalarıyla paylaşmalarını, bu görüşleri diğerlerinin dinleyip anlamalarını, öğrencilerin birbirlerini dikkatli ve saygılı bir şekilde dinlemelerini sağlamanın kolay olmadığını belirtmektedir. Öğrencilerin akademik kanıtlarını gerekçelendirmeleri ve başkalarının gerekçelerini değerlendirmeleri konusunda aynı zamanda grupta yer alan öğrencilerin birlikte akademik argümanlar (kanıtlar) oluşturmaları süreçlerinde birçok zorluklar bulunmaktadır. Bu niteliklere sahip bir tartışmayı başarıyla yürütebilen öğretmenler azınlıktadır." (Michaels, S., Sohmer, R.E., O'Connor, M. C., 2008, s. 2351). "Akademik üretici konuşma, sosyal, psikolojik ve bilişsel boyutlar içerir. Birçok öğretmen, AT'yi sadece çok başarılı olan bazı öğretmenlerin yürütebileceğini, büyük ölçekli bir boyutta uygulanamayacağını (bütün öğretmenlerin yapamayacağını) düşünmektedir (Michaels ve O'Connor, 2015, s. 334)."

AT uygulamasını öğretmenlere öğretmek için seminerler düzenlenmektedir. Aynı zamanda bir uygulama el kitabı da hazırlanmıştır. Bunun yanı sıra öğretmenlerin uygulama sırasında çeşitli durumlarda kullanabilecekleri "hazır konuşma kalıpları" oluşturularak öğretmenlere yol gösterilmesi amaçlanmıştır. Bu kapsamda uygulama sürecinde yapılması gerekenler şöyle sıralanabilir:

1. Uygulamadan önce ders kitabı dışında bir metin kullanılacaksa tartışmaya uygun metin seçimi yapılmalıdır.

2. Derste gerçekleştirilmesi beklenen bilişsel hedefler belirlenmeli, incelenen metin aracılığıyla öğretmenin özellikle öğretmek istediği konular varsa bunlar listelenmelidir.

3. Bilişsel hedeflere göre AT'nin hangi formatta uygulanacağı belirlenmelidir. Konu sınıf tartışması, küçük grup tartışması ve akran tartışması formatlarından hangisine uygunsa o format seçilmelidir. Öğretmen AT'de sınıf tartışması formatını kullanırken önemli bir noktada durup akran tartışması da yaptırabilir. Bu durumda, hangi noktada akran tartışması yaptıracağııı, öğrencilerin hangi konu üzerinde düşünmelerini isteyeceğini önceden belirlemelidir. Akran tartışması çok uzun sürerse ve öğrenciler kontrolden çıkarlarsa ne yapılacağını, akran tartışmasından sonra sınıf tartışması çok zengin hâle gelirse (çok fazla görüş ortaya çıkar, ya da konunun içeriği zenginleşirse) konuyu özetlemek, önemli noktaları belirtmek için zaman kalıp kalmayacağını hesaplamalıdır.

4. Öğretmen tartışma sırasında tartışmaya ne oranda müdahale edeceğini, öğrencilerin mi yoksa kendisinin mi tartışmayı daha çok yönlendireceğini planlamalıdır. Süreçte öğrencilerin metinle ilgili sorular üretmesi beklenmektedir fakat öğretmen de özellikle tartışıımasını istediği konularla ilgili veya tartışma sırasında öğrencilerin soru üretememesi hâlinde tartışmanın duraksamaması için sorular hazırlayabilir. Öğretmen tartışma sırasında olası durumları hesaplamalı ve bu durumlarda neler yapacağına karar vermelidir (Michaels, O'Connor, Hall, ve Resnick, 2010, s. 12).

Öğretmen tartışmayı planlamak için kendisine şu soruları sormalıdır:

- Bu soru veya problem, tartışmayı sürdürmek için yeterince zengin mi? Öğrencilerin bu soruya cevap verirken mantıklı görüşler öne sürmelerine, akıl yürütmelerine yardımcı olmak için neler yapmalıyım?

- Öğrencilere bu derste öğretmek istediğim anahtar kavramlar nelerdir? Tartışmada odaklanacă̆ım önemli fikirler nelerdir? Bu fikirlerin, yapılacak uygulamayla bağlantısı nasıl kurulacak?

- Metinde öğrencilerin ne yapacaklarını anlamamalarına neden olabilecek, problem yaratacak terimler, kelimeler var mı?

- Öğrencilerin sorularıma cevap olarak verecekleri olası cevaplar, görüşler, teoriler, tahminler veya varsayımlar nelerdir? 
- Öğrencilerin vereceği olası cevaplara nasıl karşılık veririm? Örneğin, bir öğrenci doğru cevabı birdenbire söylerse, cevabı doğru diye mi değerlendirmeliyim yoksa cevabı bir süre askıda mı bırakmalıyım?

- Birden fazla doğru yorum veya cevap olursa birçok farklı düşünce masaya yatırılabilir. Tartışmada böyle bir durumun oluşma ihtimali nedir?

- Bu soru veya problem, sınıf tartışmasına mı yoksa küçük grup tartışmasına mı daha uygun? Öğrencilere ilk başta bireysel olarak hazırlık yapmalarını daha sonra grup hâlinde tartışmalarını mı söylemeliyim yoksa hemen tartışmayı mı başlatmalıyım?

- Aynı anda birkaç öğrenci soruya cevap vermek isterse hangi öğrencinin ilk olarak görüşünü gruba sunmasını isteyeceğim?

- Tartışmada akademik bir dil kullanımı yerine günlük konuşma dili kullanılmaya başlanırsa ne yapacağım?

- Tek doğru cevabı bulunan sorularda veya yorum gerektiren sorularda nasıl davranacağım?

- Sadece birkaç öğrenci konuşmak isterse ya da birkaç kişi tartışmada baskın olursa ne yapacağım?

- Tartışma çok verimli gidiyorsa devam etmesine izin mi vermeliyim yoksa daha önce planladığım sürede bitirip konuyu özetlemek, konuşulan önemli noktaları belirtmek, ortaya çıkan sonuçları, birlikte üretilen yeni düşünceleri tekrarlamak için süre mi ayırmalıyım? (Michaels , O'Connor, Hall ve Resnick, 2010, s. 13-14).

Michaels, O‘Connor ve Resnick (2005) öğretmenlerin tartışma yöntemini uygularken yaşadıkları problemleri tespit etmiş ve bu problemlerin giderilmesi amacıyla "hazır konuşma kalıpları" diğer bir adlandırmayla "Tartışmayı Yönlendiren Kalıp ifadeler"i (Talk Moves) hazırlamışlardır. AT modelini uygulayan öğretmenlerle ilgili yapılan araştırmalar, modelin uygulanma başarısının öğretmenlere göre değişiklik gösterebildiğini ortaya koymaktadır. Öğretmenlerin konuşma kalıplarını kullanma sıklığı tartışmanın niteliğini artırmaktadır. Bu konuşma kalıplarını her öğretmen aynı düzeyde kullanmamaktadır. Wolf, Crosson ve Resnick'in (2006) araştırmasına göre öğretmenler BDKS ve EDKS aşamalarıyla ilgili kalıp ifadeleri sıklıkla kullanmış fakat katılımcıların görüşlerini bağlantılı hâle getirmekle ilgili olan ÖTKS aşamasına ait konuşma kalıplarının kullanımında aynı sıklığa ulaşılamamıştır (Wolf, Crosson ve Resnick, 2006, s. 17-18). Ouellette, Kathleen M. (2006) araştırmalarında; AT'yi uygulayan öğretmenlerin eleştirel düşünme ve doğru bilgiyi artırmada başarılı olduklarını, öğrenme topluluğu oluşturma konusunda zayıf kaldıklarını ortaya koymuşlardır. Öğretmenler, öğrencilerin görüşlerini birbiriyle bağlantılı hâle getirmekten daha çok öğrencilerin görüşlerini açıklamalarına yoğunlaşmışlardır. Öğretmenlerin öğrencilerle yaptıkları uygulamalar sırasında bu üç boyutun tamamına değinmeleri zaman almaktadır. Örneğin görüşlerini gerekçelendirmeyi başaran bir öğrenci grubunda konuşmaya diğer arkadaşlarını da katmaları daha sonraki adımda istenebilir. Bilgi sunarken kaynak belirten bir öğrenci grubunun dinledikleri bilginin doğruluğunu sormaları daha sonraki adımda gerçekleştirilebilir. Bütün becerilerin bir anda hızı bir şekilde kazanııması mümkün olmamakla birlikte öğretmenlerin bu 3 aşamaya uygun konuşma kalıpları aracılığıyla zaman içerisinde modelin bütün kurallarını uygulamaya geçirmeleri beklenmektedir.

\section{Akademik Tartışma Modelinin Aşamalarına Göre Hazırlanan “Konuşma Kalıpları}

"Hazır Konuşma Kalıpları" AT'nin 3 boyutuna göre aşağıdaki şekilde sınıflandırılmıştır:

\section{Öğrenme Topluluğuna Karşı Sorumluluk Aşamasına Uygun Kalıp ifadeler}

Öğretmen bütün öğrencilerin birbirlerini duyabilecekleri bir ortam oluşturmalıdır. Böylece gruptaki herkes birbirlerini duymanın ve kendilerini duyurmanın önemi fark etmelidir. Öğretmen bunu sağlamak için gerektiğinde, "Arkadaşınızın söylediklerini herkes duydu mu?" diye sorabilir. Herkesin aynı konuya odaklanmasını sağlamak için öğrencinin ileri sürdüğü görüşlerini açıklamasını veya tekrar etmesini isteyebilir. Öğrencilerin görüşlerini birbirlerinin görüşleri üzerine inşa etmelerini sağlamak için "Arkadaşınızın bu görüşüne kimler katılıyor, kimler katılmıyor, neden? Arkadaşınızın söylediklerine farklı görüşler eklemek isteyen var mı?" tarzında sorulardan yararlanabilir. Öğretmen gerektiğinde, öğrencilerin söylediklerini tekrar ederek, onlara yeniden söyleyerek (revoicing) (Yani, şöyle şöyle 
olduğunu söylüyorsun, değil mi? gibi ifadeler kullanarak) iddiayı onaylayabilir veya açıklığa kavuşturabilir. Bu sayede öğrenci kendi görüşünün doğru anlaşılıp anlaşıımadığını belirleyebilir ve gerekirse düzeltme imkânı bulur (Michaels, O’Connor, Hall ve Resnick, 2010, s. 29).

\section{Öğrencilerin Dikkatini Açık Tutmak}

Öğretmen arkadaşlarını dinlemeleri ve dinlediklerini hatırlamaları gerektiğini göstermek için konuşmacıya "Herkesin seni duyabilmesi için daha yüksek bir sesle tekrar söyler misin?", dinleyici konumundaki öğrencilere ise "Arkadaşınız ne söyledi?" gibi sorular yöneltebilir. Dinleyici konumundaki öğrencilere, konuşan arkadaşlarının söylediklerini kendi cümleleriyle tekrar ettirmesinin iki amacı vardır: birincisi öğrencinin dikkatini ve ne anladığını ölçmek, ikincisi ise öğrenciyi arkadaşlarının söylediklerini zihinlerinde işlemden geçirmelerine yöneltmektir. Öğrencilerden biri bir arkadaşına katıldığını ifade ettiğinde hem arkadaşına saygı duyduğunu hem de kendi görüşlerini arkadaşının görüşleri üzerine bina ettiğini göstermiş olur. Diğer öğrenci de kendi görüşü üzerine yapılandırılmış yeni görüşü dinlediğinde tartışma yapılandırılır ve gelişir (Michaels, O'Connor, Hall, ve Resnick, 2010, s. 29).

\section{Görüşleri Birbiriyle Bağlantıı Hâle Getirmek}

Öğrencilerin kendilerinden önce söylenenle, kendi söyleyecekleri arasında bir bağlantı kurmak için bir yapı oluşturmaları gerekir. "Herkes katılıyor mu?", "Kim katılmıyor?", "Arkadaşınızın bu söylediklerine kim bir şeyler eklemek ister?" türünden kalıp ifadeler, öğretmenin öğrencilerin görüşleri arasında bağlantı kurmasını sağlar. Öğrencilerin, sadece birbirlerini duymalarını değil aynı zamanda konuşmacının söylediklerini anlamaları gerekir. "Arkadaşının söylediklerini kendi cümlelerinde tekrar eder misin?", "Arkadaşının bu söyledikleri senin söylemeye çalıştığın şeyler miydi?” türünden sorular herkesin aynı noktaya odaklanmasını sağlar.

\section{Onaylamak ve Açıklamak}

Öğretmen öğrencilerin görüşlerini onaylamalı ve açıklamalı, öğrencilerin de böyle davranması için model olmalıdır. Öğretmen böylece hem konuşmacıları hem de dinleyenleri verimli bir konuşmanın içinde tutabilir. Bunu yapmanın bir yolu "tekrar etmek"tir (revoicing). “... olduğunu söylüyorsun?" tarzında sorular yoluyla kendi söylediklerini tekrar ettirmek öğrenciye söylediklerini pekiştirme ve söylediklerinin nasıl anlaşıldığını duyma fırsatı verir, ÖTKS aşamasına uygun şekilde hazırlanan sorular, öğrencilerin söylediklerinin başkaları tarafından doğru bir şekilde anlaşılmasını sağlama sorumluluğunu hissetmesine yardımcı olur. Öğrenci bu sayede olabildiğince net bir şekilde kendini ifade etmeye çalışır (Michaels, O'Connor, Hall ve Resnick, 2010, s. 29-30).

\section{Bilginin Doğruluğuna Karşı Sorumluluk Aşamasına Uygun Kalıp ifadeler}

Öğretmen öğrencileri doğru ve yeterli bilgi sunmaları için yönlendirmelidir. Bu amaçla "Bu konu hakkında ne biliyoruz?", "Kanıtımız ne?", "Doğru sonuca nasıl ulaşabiliriz?" soruları sorulabilir. Öğrencilerin konuşmalarını bilgileri üzerine yapılandırmaları için; "Önceki konuyu hatırlıyor musunuz çocuklar? Bu konuyla daha önce öğrendikleriniz arasında nasıl bağlantı kurarsınız?" şeklinde sorular yöneltebilir.

Okulda zamanla bilgi birikimi arttıkça bu alışkanlıkların ve pratiklerin etkisi de doğal olarak yaygınlaşacaktır (Michaels, O'Connor, Hall ve Resnick, 2010, s. 30).

BDKS boyutunda kullanılabilecek kalıp ifadeler, aşağıdaki amaçlara ulaşmada yardımcı olur:

Doğru Bilgi Sunulması için Baskı Yapmak

Öğretmenler, öğrencilerin sundukları bilgilerin doğru, geçerli ve açık bilgiler olmasını sağlamak için "Bu doğru olabilir, söylediklerinle ilgili başka kanıtlar da sunabilir misin?", "Geçen ay okuduğumuz kitapta bununla ilgili bir yer vardı, bakalım mı?", "Bu konuda nasıl daha fazla bilgi edinebiliriz? Kim bu görevi üstlenmek ister?", "Bu verilerin/bilgilerin doğru olduğundan emin misin?", "Bu bilgileri metinde nerede bulabiliriz?" sorularını sormalıdır (Michaels, O’Connor, Hall ve Resnick, 2010, s. 30-31).

Önceki Bilgilerle Bağlantılar Kurmak

Öğretmen, öğrencilere sınıfta daha önce geçen bilgilerle bağlantı kurabileceklerini, daha önceki deneyimlerine dayanabileceklerini hatırlatır ve öğrenciler de iddialarını, argümanlarını daha önceki 
bilgilere atıf yaparak sunarlar (Michaels, O'Connor, Hall ve Resnick, 2010, s. 31). Ön bilgilerle bağlantı kurmak için "Daha önce bu konuyla ilgili öğrendiklerimizle bu konu arasında nasıl bir bağlantı var?", "Bu konuyla ilgili ne biliyorsunuz?", "Daha önce bu konuyla ilgili bir kitap okudunuz mu?", "Geçen hafta buna benzer bir konu tartışmıştık, sizce önceki tartışmada öğrendiğimiz bilgileri bu tartışmada kanıt olarak kullanabilir miyiz?" şeklinde sorularla önceki bilgilerle bağlantı kurulmalıdır.

\section{Etkili Düşünmeye Karşı Sorumluluk Aşamasına Uygun Kalıp ifadeler}

Öğretmen, öğrencilerin görüşlerinin kalitesine odaklanarak öğrencilerin açık ve mantıklı bağlantılar kurma becerilerini geliştirmek için "Neden böyle düşünüyorsun?", "Söylediğin gerçekte ne anlama geliyor?", "Söylediklerini nasıl kanıtlarsın?" sorularını sorabilir.

\section{Muhakeme Yapmak}

Öğretmen, öğrencilerin daha muhakeme yapma kabiliyetlerini geliştirmek için: "Bu konu hakkında biraz daha konuşabilir misin? Zamanın var, bekleyeceğiz" diyerek ona düşünme ortamı yaratır (Michaels, O'Connor, Hall ve Resnick, 2010, s. 31). Öğrencilerin tartışmada sunulan bilgilerle görüşleri karşılaştırarak değerlendirme yapmaları için "Bu konuyla ilgili sunulan bilgiler ve iddialar doğrultusunda nasıl bir sonuca varabiliriz?", "Bilgilerle iddialar tutarlı mı?” vb. sorular sorulmalıdır.

\section{Gerekçeler Sunmak}

Tartışma sırasında sadece yorum yapmak yeterli değildir, eğer bir yorum yapılacaksa veya hangi sonuca varıldığı ifade edilecekse bu sonuca/yargıya nasıl ulaşıldığını açıklamak için gerekçeler mutlaka belirtilmelidir. Eğer bir öğrenci sınıfta başka bir arkadaşının görüşlerini desteklemek istiyorsa aynı şekilde bir kaynağa, gerekçeye dayanmalıdır. Öğretmen, kanıt ve gerekçe kullanımını sağlamak için bir öğrencinin görüşüyle ilgili diğer öğrencilerin yorum yapmalarını isteyerek konuyu daha geniş bir grupla tartıştırabilir (Michaels, O'Connor, Hall ve Resnick, 2010, s. 31). Bu nedenle bir görüş öne sürüldüğünde "Böyle düşünmenin sebebi nedir?", "Bu iddianı nasıl gerekçelendirirsin?", "Bu sonuca nasıl vardın?" vb. sorular sorulmalıdır.

\section{Tartışma ve Sonuç}

Öğrenciler metin üzerine konuşarak kendi görüşleriyle metni yeniden üretmektedirler. AT, öğrencilerin metin aracılığıyla düşünme becerilerini geliştiren iletişime dayalı bir model olduğu için öğrencilerin iletişim becerilerini geliştirmekte, öğrencileri aynı zamanda sosyal yönden de daha dışadönük ve girişken hâle getirmektedir.

AT ile ilgili çalışmaların geliştirilmesi ve öğretmenlere hizmet içi eğitim yoluyla öğretilmesi modelin okullarda daha fazla uygulanmasını sağlayacaktır. Yurt dışında yapılan çalışmalar öğretmenlerin modelin bütün özelliklerini uygulamada aynı başarıyı gösteremediklerini ortaya koymuştur. Başarılı bir tartışma uygulaması için öğrencilerin modelin özelliklerini kavraması, öğretmenin tecrübeli olması beklenmektedir. Hâlihazırda öğretmenlerin öğrencilerle nasıl iletişim kurdukları ön plana alınırken öğrenci-öğrenci iletişimi göz ardı edilebilmektedir. Öğretmenlere öğrenciler arasındaki iletişimi güçlendirme konusunda eğitim verilmesi, sınıf içerisinde bütün öğrencilerin katıldığı eğitim uygulamalarını yürütmelerinde kolaylık sağlayacaktır.

Sınıf içerisinde bir tartışma uygulaması yapmak; sadece metne hâkim olmak ve metinle ilgili soru hazırlamanın ötesinde grupta yer alan öğrencilerin tanınması, baskın olan ve çekingen öğrencilerin belirlenmesi, bütün öğrenciler arasında bir denge kurulması, dersle ilgili olmayan öğrencilerin de ilgilerini çekecek bir tartışma ortamı yaratılması gibi birçok ayrıntıya dikkat etmeyi gerektirir. Çekingen öğrenciler söz hakkı aldığında grup içerisindeki diğer öğrencilerin olumlu yorum yapmaları bu tür öğrencileri motive etmektedir. Bu nedenle grup içerisinde öğrencilerin birbirlerinin görüşleriyle ilgili yorumlar yapmaları bu öğrencilerin tartışmaya katılmalarını olumlu etkilemektedir. Tartışmaya katılmayan çekingen öğrencilerin tartışmaya nasıl dâhil edileceğiyle ilgili başka araştırmalar yapılabilir.

Sınıfların kalabalık olması tartışma uygulamalarını güçleştirmektedir. Bu sorunun çözülmesi için önce küçük grup tartışması yaptırıp daha sonra bütün sınıfla tartışma yaptırılması denenebilir. Bu kapsamda, akvaryum tekniği (fishbowl) gibi tekniklerden de yararlanmak mümkündür. Göz teması kurmak tartışmada önemli olduğu için bütün öğrencilerin birbirlerini görebilecekleri bir düzende oturmaları mevcut sınıf düzeyinde mümkün olmamaktadır. Bu sınırlılıkların aşılması için öğrencilerin 
bir daire oluşturacak düzende oturmaları, bu şekilde bir düzen oluşturma imkânı olmadığında konuşan kişiye dönük olarak onu ilgiyle dinlemeyi öğrenmeleri sağlanmalıdır. Tartışma sırasında özellikle ilk haftalarda öğrencilerin yalnızca öğretmene dönük olarak ve öğretmene hitaben konuştukları görülmektedir. Öğretmenin olduğu bir ortamda öğrencilerin birbirlerine hitap ederek, vücut diliyle de birbirlerine dönük olarak bir konuşma alışkanlığı kazanmaları zaman almaktadır. Kalabalık sınıflarda modelin uygulanma sürecinde yaşanan zorlukları ortaya koyan çalışmalar yapılarak, modelin Türkiye şartlarında kullanılabilirliğini artıracak çözümler ortaya koyan çalışmalara ağırlık verilebilir.

Ders kitaplarında metin üzerine tartışmayla ilgili etkinlikler yer almamaktadır. Metinle ilgili bazı sorular öğrencilerin tartışmalarına uygun olarak düzenlenmiştir fakat sınıfta metin üzerine bir tartışma uygulaması yapılıp yapılmaması öğretmenin tercihine bırakılmıştır. Metin üzerine tartışmayla ilgili olarak kuralları ve çerçevesi belirli tartışma modellerine ders kitaplarında yer verilerek öğrencilere bu yaklaşımla öğrenme imkânı sunulabilir.

Sınıf içerisindeki farklı derslerde yapılan tartışmaların deşifre edilerek öğrencilerin kanıtlara dayanmaları, bilgi sunmaları, argümanlar oluşturmaları, verilen bilgileri muhakeme ederek sonuçlara ulaşmaları vb. konulardaki yeterliliklerini inceleyen çalışmalar bulunmamaktadır. Okullarda yapılan tartışmalar incelenerek akademik düzeyde tartışmaların yapılma durumu araştırılabilir.

\section{Araştırma ve Yayın Etiği}

Bu çalışmada "Yükseköğretim Kurumları Bilimsel Araştırma ve Yayın Etiği Yönergesi" kapsamında uyulması belirtilen tüm kurallara uyulmuştur. Yönergenin ikinci bölümü olan "Bilimsel Araştırma ve Yayın Etiğine Aykırı Eylemler" başlığı altında belirtilen eylemlerden hiçbiri gerçekleştirilmemiştir.

\section{Yazarların Katkı Oranı}

1. yazar $\% 60$, 2. yazar $\% 40$

\section{Çıkar Çatışması}

Çıkar çatışması teşkil edebilecek durumlar ve ilişkiler yoktur.

\section{Kaynaklar}

Bellamy, L. (2016). Classroom environment: Content analysis examining characteristics of classroom environments that affect student's academic achievement (Unpublished doctoral dissertation). East Tennessee State University, Educational Leadership, Johnson City, USA.

Boston University, School of Education Research. (2004). Project challenge: Identifying and developing talent in mathematics within low-income urban schools. Chapin, S., \& O'Connor, M. C. tarafından yazılmıştır. (Rapor numarası: 1, 1-6).

Carpenter, L. A. (2014). Engaging students in authentic discussion in the secondary English classroom (Unpublished doctoral dissertation). University of Rhode Island and Rhode Island College, Kingston, USA.

Cazden, C. B. (2001). Classroom discourse: The language of teaching and learning. Portsmouth: Heinemann.

Gillies, R. M. (2014). Developments in cooperative learning. Anales de Psicología, 30, pp. 792-801.

Guardado, D. (2017). Multicultural literature discussions: A study of comprehension (Unpublished master's thesis). Faculty of the Kalmanovitz School of Education Saint Mary's College of California, California, USA.

Howell, P. B., Thomas, S. \& Ardasheva Y. (2011). Talk in the classroom: Meeting the developmental, academic and cultural needs of middle school students. Middle Grades Research Journal, 6(1), pp. 47-63.

Learning and Research Development Center, University of Pittsburgh. (2006). Accountable Talk in reading comprehension instruction CSE Technical Report 670. Wolf M. K., Crosson. A.C., \& Resnick L. B. tarafından yazılmıştır. (Rapor numarası 670). 
Martello, N. E. (2015). The democratization of talk: A qualitative study of middle school English language arts teachers' and students' narrations on the equal access of Accountable Talk (Unpublished doctoral dissertation). The University at Buffalo State University of New York, New York, USA.

Michaels, S., O'Connor, C., \& Resnick, L. B. (2008). Deliberative discourse idealized and realized: Accountable Talk in the classroom and in civic life. Studies in philosophy and education, 27(4), pp. 283-297.

Michaels, S., O'Connor, M. C., Hall, M. W., \& Resnick, L. B. (2010). Accountable Talk sourcebook: For classroom conversation that works. Pittsburgh: University of Pittsburgh Institute for Learning.

Michaels, S., Sohmer, R., \& O'Connor, M. (2008) Discourse in the classroom. In U. Ammon, N. Dittmar, K. Mattheier \& P. Trudgill (Ed.), An international handbook of the science of language and society (pp.2351-2366). Berlin-New York: De Gruyter Mouton.

Michaels, S., \& O'Connor, C. (2015). Conceptualizing talk moves as tools: Professional development approaches for academically productive discussions. In L. B. Resnick, C. S. Asterhan, \& S. N. Clarke (Ed.), Socializing intelligence through talk and dialogue (pp. 347-362). Washington: American Educational Research Association.

Monaghan, J. R. (2015). Scaffolds in a middle school science classroom: Problem-based learning and field trip experience (Unpublished doctoral dissertation). The State University of New Jersey, The Graduate School of Education, Rutgers.

Ouellette, K. M. (2006). Pedagogical perceptions of teachers: The use of Accountable Talk in Mathematics classrooms with students of color (Unpublished doctoral dissertation). University of Hartford, Nursing and Health Professions, West Hartford, USA.

Özçetin, K. (2019). Akademik Tartışma Modelinin Türkçe derslerinde kullanılabilirliği üzerine bir durum araştırması (Yayımlanmamış doktora tezi). Marmara Üniversitesi Eğitim Bilimleri Enstitüsü, İstanbul.

Richardson, A. E. (2010). Exploring text through student discussions: Accountable Talk in the middle school classroom. English Journal, 100(1), pp. 83-88.

Tegos, S., Demetriadis, S., \& Karakostas, A. (2015). Promoting academically productive talk with conversational agent interventions in collaborative learning settings. Computers \& Education, 87 , pp. 309-325.

\section{Introduction}

\section{Extended Abstract}

This article aims to provide information about the Accountable Talk (AT) model which was created by Resnick, Michaels, and O'Connor in 1997. Resnick created the Teaching and Learning Profiles as a result of her research and created the Principles of Learning based on those.

\section{Dimensions of Accountable Talk}

For classroom talk to promote learning, it must be accountable to the learning community, accurate knowledge, and rigorous thinking (Michaels, O'Connor, Hall and Resnick, 2010, s. 1).

In being accountable to the learning community, students follow rules of discussion, build their ideas upon their partners' ideas, listen to and learn from one another. Accurate knowledge means that students should support the validity of their contributions by explicitly basing their claims on the pool of knowledge accessible to the group (e.g. their textbooks). Rigorous thinking entails that students focus on logically connecting their claims in a reasonable and rigorous manner, assessing the logic of their arguments, and drawing valuable conclusions (Tegos, Demetriadis and Karakostas, 2015, s. 310).

\section{Accountability to the Learning Community (ALC)}

This is talk that attends seriously to the ideas of others and builds on them. Participants listen carefully to one another, build on one another's ideas, and ask each other questions aimed at clarifying or expanding a proposition. When the talk is accountable to the community, participants listen to others and build their contributions in response to those of others. They may extend or elaborate on 
someone else's argument, or ask someone for the elaboration of an expressed idea (Michaels, O'Connor and Resnick, 2008).

\section{Accountability to Accurate Knowledge (AAK)}

The information presented during the discussion phase needs to be accurate, qualified, and functional to clarify the subject. The way information is used is just as important as the veracity of the information being presented. The speaker should present directly relevant and verified information, rather than saying anything that comes to his mind while expressing his views or making a claim. Consistently citing sources throughout the discussion increases the accuracy of the information. In this process, the nature of the cited source should be reviewed.

\section{Accountability to Rigorous Thinking (ART)}

This dimension encompasses reaching logical conclusions by synthesizing the information and views presented during the discussion, incorporating every new piece of information learned in the process. This dimension aims to develop students' reasoning power. The effective use of the three dimensions of AT cultivates a healthy discussion environment and, as a result, qualified learning occurs.

ART emphasizes logical connections and the drawing of reasonable conclusions (Michaels, O'Connor and Resnick, 2008, s. 286). When classroom talk is held to rigorous thinking standards, students and teachers consistently push for clear statements of claims (positions, explanations, or predictions) and sound reasoning in backing up those claims with evidence. Teachers and students examine evidence critically, knowing that just having accurate facts is not, in and of itself, enough (Michaels, O'Connor, Hall and Resnick, 2010). Evidence must be of good quality and value. Evidence must be reliable and relevant to the claims being addressed.

\section{Talk Moves}

Michaels and O'Connor built sets of foundational goals which are obvious but important requirements that underlie any academically productive discussion. In the Four Goals for Productive Discussions which are Helping Individual Students Share Their Own Thoughts, Helping Students Orient to and Listen Carefully to One Another, Helping Students Deepen Their Reasoning, and Helping Students Engage with Others' Reasoning, the authors suggest that conceptualizing talk moves as tools provide teachers with a useful construct for facilitating academically productive talk (Michaels and O'Connor, C., 2015). "By scaffolding students' responses and contributions, teachers can quickly make a difference in the level of rigor and productivity in classroom talk. There are a number of 'moves' teachers can use to promote accountability to community, knowledge, and rigorous thinking" (Michaels, O'Connor, Hall and Resnick, 2010). Some examples of teacher moves are, "Did everyone hear that?", "Who wants to add on...?", "Where can we find that?", "How does this connect?", "Why do you think that?" etc.

\section{Results and Discussion}

AT develops students' thinking skills by discussing assigned texts. Since it is a communicationbased model, it also improves students' communication skills. It also encourages students to be more extroverted and sociable. Furthering the studies on AT and teaching it to teachers through in-service training will enable the model to be applied more in schools. Unfortunately, crowded classrooms make discussion practices difficult. In order to solve this problem, it may be worth breaking the class into small discussion groups prior to engaging the whole class in one discussion. Discussion models with specific rules and the framework regarding the discussion of texts should also be included in textbooks. 